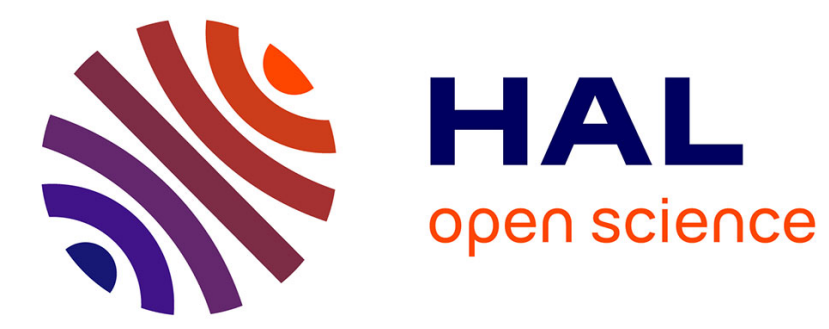

\title{
Digital Healthcare
}

Carine Milcent

\section{To cite this version:}

Carine Milcent. Digital Healthcare. Carine Milcent. Healthcare Reform in China. From violence to digital healthcare, Springer, pp.191-223, 2018, 10.1007/978-3-319-69736-9_9 . halshs-01885441

\section{HAL Id: halshs-01885441 https://shs.hal.science/halshs-01885441}

Submitted on 20 Jan 2022

HAL is a multi-disciplinary open access archive for the deposit and dissemination of scientific research documents, whether they are published or not. The documents may come from teaching and research institutions in France or abroad, or from public or private research centers.
L'archive ouverte pluridisciplinaire HAL, est destinée au dépôt et à la diffusion de documents scientifiques de niveau recherche, publiés ou non, émanant des établissements d'enseignement et de recherche français ou étrangers, des laboratoires publics ou privés. 


\title{
Digital Healthcare
}

\author{
Prof. Carine MILCENT \\ Carine.milcent@psemail.eu \\ CNRS - PSE
}

As described through the different chapters of this book, the Chinese healthcare system faces many issues such as confrontational relationship between doctors and patients, lack of access in rural areas, significant mark-up throughout distribution channels, financial heavy burden for chronic diseases, poor quality of supply healthcare and inefficient hospital operations except level-3 hospital that have to deal with an over-demand. So far, solutions have been proposed as multiplication of healthcare suppliers, establishment of general practitioners as gatekeepers for hospital admission, the implementation of public health insurance schemes or government support with reforms in favor of private health insurance and private healthcare providers. However, they have not proven sufficient to solve all problems yet.

In this chapter, I present how the digital health may be part of the response to inefficiencies of the healthcare system. One of the strengths of the e-health is the mass adoption of mobile platforms. In 2011, there already were 500 million of internet users, 180 million of online buyers and 300 million users of social networks. In 2014, US\$ 700 million were invested in e-health firms. McKinsey Global Institute report (2015) gave other figures shedding light on the rapid growth of the mobile health sector in China. $83 \%$ of internet users are mobile phone internet users. The number of active smart devices was 700 million in 2014, with around 3 hours spent on smart phone every day ${ }^{1}$, making the potential for e-health huge. According to the Boston Consulting Group, the market is expected to be worth over US\$ 110 billion by 2020 . This market is wide in scope as it covers, on top of smartphone applications, cloud computing, as well as applications using «big data ». There are over 2,000 healthcare related smart phone applications on the market. Some of these applications are targeted at physicians and healthcare institutes, while others are aimed at patients. For patients, the most frequently used applications are for telemedical consulting, teleconsultation, diagnosis services and treatment services. These services are modifying the behaviour of each of the four actors of the health actors: Patients, Physicians and medical staff, Insurers, Pharmaceutical companies.

The government accelerated its support to e-health services and devices from the 2009-reform. With the $12^{\text {th }}$ five-year plan, regarding medical equipment industry, the MoC said "the latest technologies in digitalization, internet, and cloud will be the key for electronics healthcare development". The MoH, in the Strategic Report on Healthy China 2020, planned a USD 9.8 billion budget to standardize IT system in major hospitals, building a public Electronic Medical Record (EMR) system and regional medical information platform. The guideline for Remote

\footnotetext{
${ }^{1}$ China Mobile Internet 2013 overview. Umeng Insight Report, March 2014.
} 
Medical Service from NHFPC, published in August 2014, allowed online service providers to offer medical suggestion but so far, only healthcare institutions can provide remote medical treatment. In January 2015, telemedicine pilot programs have been launched in 5 provinces, amongst most remote of China (Ningxia, Yunnan, Inner Mongolia, Guizhou, and Tibet).

\section{Context information}

\section{Smart phone usage and Apps}

In China more than anywhere, smartphones have totally transformed the way people communicate and consume. To get access digital services, a vast majority of Chinese consumers use their mobile phone. On the essential and vital apps is WeChat. Adding a correspondent could be in adding a contact phone number or in scanning the QR code provided by WeChat app. Everyone communicates via this free app (phone, video, messages). It can be a one-to-one communication or group of people chatting together simultaneously. They disseminate information with files, pictures, photos, audios. They exchange opinions through private or semiprivate network. They can buy products and services (the bank details can be linked) but also use a virtual money that is used for reimbursing a sharing diner or group gifts. The key success of this app is the personal QR code that can be scanned as easily as taking a photo. The editor of this app, Tencent, has turned into a major player of the industry and diversifies its activity into an ever-increasing number of activities.

Alibaba and Baidu are also widely present through different apps. Their apps are focusing on specific areas that makes the main difference with WeChat app. In the following, we will see how Alibaba provides a booking registration system that allows streamlining the hospital queuing processes. We also present apps of Baidu that make online consultation as easy as a phone call to a friend. Some other apps allow getting information on the patient's health status. If some apps help the medical staff to follow-up her health condition evolution, some others provide information to the individual herself to foster her way of life for a better health.

\section{Institutional changes}

The National Health and Family Planning Commission of the People's Republic of China (NHFPC) published on August $29^{\text {th }}, 2014$, its opinions regarding telemedicine services. This document promoted a more intensive use of the telemedicine over the Chinese territory.

Yet, support to telemedicine from the Chinese authorities had appeared earlier, as early as 1999, with a notice of the former ministry of health $(\mathrm{MoH})^{2}$. If the definition was quite restrictive in the earlier part of the first decade after 2000, the new notices since then were more inclusive. The

\footnotetext{
« Notice on Reinforcing the Administration of Telemedicine », Health Office Issue 1999(2)
} 
2014 Notices widely expanded the telemedicine definition to procedures, diagnoses, patient follow-up and doctor communication.

In 2013, according to the official published statistics of NHFPC, more than 2,057 medicine institute called on telemedicine to treat patients.

Since 2010, the financial authorities of the central government have invested ¥84.28 million Yuan, in supporting 22 Midwestern provinces in setting up telemedicine systems ${ }^{3}$.

It reflects the endeavour of the Chinese government to make the use of the telemedicine by medical institutions more widespread. The remote healthcare access can be interpreted as an alternative used by the Chinese authorities to deal with geographic disparities observed over the territory. Its goes simultaneously with the wide development of public health centres, which can be interpreted as a mixed solution involving both physical resources (extensive network of health centres) and digital resources (online telemedicine).

Since the first notices on telemedicine, the provincial Health and Family Planning Commissions got a certain degree of flexibility, with little strong direction from the central government. As a result, each Chinese province has defined its own standards for content and implementation. The consequence is a wide disparity in the internet platforms that are implemented. Hospitals are then poorly connected from one province to the other. In addition, the reimbursement rule differs from one location to the other. Ultimately, this brings about a paradox in which telemedicine systems are entrenched in different geographical silos that cannot connect, creating a physical barrier for a digital system.

To solve this paradox, a new notice was published on January $15^{\text {th }}, 2015$ to define the broad outline of a unified telemedicine system over the Chinese territory. Each province is only in charge of the executive part of this telemedicine network 4 . In this document, the condition of privacy and confidentiality of the information is also stated. However, it remains quite general.

\section{Solving access challenges}

Before going on this section, it seems to me important to recall that the Chinese population is mainly covered by the three public health insurances. In most cases, these public insurance does not cover the out-patient expenses. Even when these expenses are covered, the out-of-pocket in percentage remains high. Therefore, the price of an outpatient medical visit is a determinant variable for healthcare access.

\section{Online appointment registration systems}

As explained earlier in this book, one of the most common complaints voiced by the Chinese population against the health system is the time spent in queues for outpatient registration. Some patients or relatives of patients have to wait in line for long hours, even overnight sometimes, to

\footnotetext{
3 The original notice from NHFPC with an English translation can be found at following address https://www.healthcarelawtoday.com/wp-content/uploads/sites/15/2014/09/China-Telemedicine-Opinions-Aug29-2014.pdf accessed September 2017

${ }^{4}$ http://www.nhfpc.gov.cn/ewebeditor/uploadfile/2015/01/20150115100526329.pdf accessed September 2017
} 
ensure registration. The ticket black market to skip part of the waiting time has spread over the country, weighting in the global context. Online appointment registration systems are seen as possibly to ease this issue, providing easier access to hospital medical services.

Several advantages can be listed:

- Avoid the long queuing lines required with the traditional queuing registration, eventually leading to an increase in the satisfaction level of patients;

- Limit the black market of registration tickets;

- Reduce the risk cross-infection developing during registration process;

- Share medical information before and after the appointment or the admission-discharge process. The patient can share any pre-analysis made through connected devices or other ways and is able to share his medical information obtained on the internet or any other sources. The physician can follow-up with the patient after the consultation or the discharge;

- The system may enhance the consistency and continuity of patient medical records. A kind of historical medical record could in theory br available for each patient;

- For hospitals, appointment systems can optimize medical procedures, realize outpatient shunts and reduce economic costs. $56,,, 8,,, 11,12,13$

The Beijing Municipal Commission of Health and Family Planning took a bold approach in December 2015: all level 3 and 3A hospitals of this province-level municipality are to offer an online registration system, with an app for mobile phone, by the end of 2017. This move aims at accelerating a trend that had already well started. Some level 3A-hospitals, for instance the Beijing Children's hospital had already introduced such online systems. Other had WeChat-based registration systems, including advanced functionalities, such as sharing blood tests results or other diagnoses to patients. According to many doctors, this system of registration has already modified the atmosphere at the hospital's entry. A doctor from Beijing Anzhen Hospital, Nie Xiaolu explains ${ }^{14}$ : «It used to be common to see more than 1,000 patients and family members queuing up in the hospital early in the morning». This hospital received 3.37 million outpatients in 2014.

\footnotetext{
${ }^{5}$ Su Y, Liu J. L, Wang Y, Yi X. M. The idea about the mode of a patient- centered modern clinic. Journal of Medical Postgraduates. 2006;19(1):74-78.

${ }^{6}$ Guo R, Miao Z. M, Wei G, Xing S. C, Zhang Y. The present situation and suggestions of the domestic appointment registration of hospital. Progress in Modern Biomedicine. 2012;12(7):1357-1360

${ }^{7}$ Huang M. Exploration and practice about outpatient appointment registration service mode. Gansu Journal of Traditional Chinese Medicine. 2011;24(1):59-60

${ }^{8}$ Yin X. Q, Huang Z. Z, Huang L. J. Design and research on appointed outpatient registration system in modern hospital. Hospital Digitalization. 2010;31(12):48-53.

${ }^{9}$ Xu Y. X, Ding H. X. Current situation analysis of the hospital outpatient appointment services. Clinical Medical Engineering. 2012;19(1):105-106.

${ }^{10}$ Yin X. Q, Huang Z. Z, Huang L. J. Design and research on appointed outpatient registration system in modern hospital. Hospital Digitalization. 2010;31(12):48-53.

${ }^{11}$ Chen J. H, Tu S. G, Xiong H, Xu N. Z. Practice of mobile phone real-name system appointment registration. Chinese Nursing Research. 2012;26(1):170-171

12 Huang M. Exploration and practice about outpatient appointment registration service mode. Gansu Journal of Traditional Chinese Medicine. 2011;24(1):59-60.

${ }^{13} \mathrm{Yu} \mathrm{W}, \mathrm{Yu}$ X, Hu H, Duan G, Liu Z, Wang Y Use of hospital appointment registration systems in China: a survey study. Global Journal of Health Sciences, 2013 ; 5(5):193-201

14 « No more long queues in China's smart hospitals », China Daily, 8 Dec 2015
} 
GuaHao is now the largest online platform in China. Founded in 2010, it is part of the Weiyi group, linked to Tencent group. GuaHao has an information-sharing system and its welldesigned, easy-to-use online platform allows patients to access their personal calendars, local hospitals, and physicians and helps them make appointments within minutes. In 2011, 8 hospitals participated and 7 million appointments were registered. Today, 1,600 hospitals are listed on its platform, with 190,000 specialists and 100 million registered users. The services offered is now extended to online service to Chinese hospitals, doctors and patients who can make hospital appointment reservations and make payment using its mobile app and web portal. The name was eventually changed to WeDoctor ${ }^{15}$, to make the link with WeChat clearer for customers.

Competition is heating up in this lucrative market. Several online scheduling systems providers have popped up in China during this last decade. However, GuaHao stands out. It has been endorsed by the National Health and Family Planning Commission of the People's Republic of China. Doing so, for the audience, a label of quality and accreditation is associated with this online provider. Consumers are then influenced in their choice of online providers. In other words, the authorisation granted to GuaHao by the NHFP gives it dominant position on the market.

Amongst the many competitors, Baidu also offers an app for patients to access physician networks and make online registration. It also allows to check patients' ratings and to provide feedback.

\section{Access to online healthcare}

Online consultation is highly developed in some countries such as in the US with 5 million users per month and 35\% of the population using internet for self-diagnosis.

The online access to healthcare can be divided into two segments of markets. The first segment aggregates information from various sources, including patient reviews, while the second and third directly propose services. The second segment focuses on personal services without mobilizing a medical staff. The third segment proposes online medical consultations.

The first segment focuses on the healthcare advises; the apps compiles a mass of data, information that would be difficult to be obtained otherwise. What I mean here by difficult is time consuming and expensive. The success of such apps is obviously based on the subjective judgment of the consumers but only on it. So far, neither a public authority nor an external authority without conflict of interests does guarantee the objective quality of the service offered. Today, there are increasing requirements of consumers for a form of accreditation.

The second segment This category is better described through concrete examples of apps that are massively used. Among the «success story » applications, Dayima is one to mention. Dayima,

\footnotetext{
15 McKinsey analysis, 2015 https:/ / fr.slideshare.net/fle864/20150402-chic-mc-k-e-health-in-china-vf accessed September 2017

http://www.iamwire.com/2015/09/practos-chinese-counterpart-guahao-raises-394m-1-5b-valuation-led-hillhousegoldman $/ 123356$

accessed September 2017

http://www.sramanamitra.com/2016/06/17/billion-dollar-unicorns-guahao-targets-chinas-healthcare/

accessed September 2017
} 
introduced in 2012, is the most popular menstruation record application in China. The basic function of this app include recording and predicting periods. Each day more than 3.2 million active visitors access the app, with 45 million of registered users.

Another popular app is Gengmei, a networking app dedicated to beauty in general and cosmetic surgery in particular. This app. offers services on the second and third segments. Users can use the app to consult with cosmetic surgeons free of charge, and obtain professional advice regarding procedures they may be considering. Advises and consulting are given by more than 3'000 physicians online. For the consumers, this is a free access and a no-delay access to cosmetic physicians in a country where healthcare access is time consuming and expensive. Online users are then incentivized to consume cosmetic products purchased online on the app. For instance, laser treatment for acne is widely available to be booked online, with a cost ranging between RMB 5,000 and 10,00016. Launched in 2013, there were more than 20 millions of users in 2016.

The third segment: as said before, in particular context in china led to concentrate the demand for in-patients as well as for out-patients into level-3 hospitals. The development of internet and of smart phones has opened new possibilities for healthcare suppliers. Faced with overcrowded level-3 hospitals where a physical consultation by a high-qualified physician is offered, the healthcare market has developed a new supply with a virtual consultation by a high-qualified physician. This supply has several advantages: the delay of consultation is drastically reduced, the price of the consultation is lower, the time of consultation is significantly longer and or complementary information can be provided with no delay by the physician. All these elements may explain the incredibly success of this new supply.

Besides, the teleconsultation is also used to get a second medical opinion after a first diagnosis. The patient can send photos, scans or files of medical information obtained during the first medical visit. This information then helps and guides the physician for the online consultation. For chronic diseases where the patient has to return regularly to consult in order to get the adequate medication, the teleconsultation is clearly seen as an improvement to the healthcare process.

From physicians' point of view, the online consultation allows them to extend their activity without wasting time in transportation. From legal and administrative standpoint, the physician belongs to a definite healthcare institution. He cannot work in a different place at the same time. However, the online consultations are considered "consulting activities" and are tolerated as such. This activity sits in a legally grey area. According to a researcher in Law at the Chinese Academy of Social Science (CASS), the current legal status of "consulting" gives flexibility to Chinese authorities to observe how things go before fixing a stricter framework ${ }^{17}$. However, it leaves many questions unanswered, among others on the responsibility when a medical error occurs.

The online consultation and the implementation of family doctors are parallel solutions to address the same issue, namely the congestion of level 3 and above hospitals. Online consultations i) brings additional healthcare supply. Contrary to the community health centers, level-1 hospitals and part of level-2 hospitals, the demand for online consultations is massive and

16 A new face for China's plastic surgery industry, May 2015, South China Morning Post. http://www.scmp.com/news/china/society/article/1799127/new-face-chinas-plastic-surgery-industry accessed September 2017

${ }^{17}$ Interviews in Beijing, October and November 2015 
increasing. The supply is judged by consumers as offering a sufficient level of quality. ii) allows to stock electronic information on patients, to keep track of historical medical health status of the patient. This information is available instantaneously by all online physicians of the website and if needed, simultaneously by several physicians. With a classical visit, the medical file can be on paper or in electronic version but the availability of the information may be less immediate. This advantage has a direct drawback: risk of mishandling of confidential information. The information disclosed by the patient for his consultation might be disseminated and used for other aims. A strong regulation has to be implemented to avoid any potential drift. iii) leads to disconnect the hospital in-patient activity from the out-patient activity. Indeed, the in-patient activity cannot be done without the physical presence of a physician.

Depending on the app, the cost of an online consultation is a fee whatever the diagnosis or monthly and annual contributions. The physician determines the pathology according to the symptom described by the patient and the possible medical information provided by the patient.

Amongst the most popular apps, we can mention Chunyu yisheng, founded in 2011. Originally, this app was only a remote physician consultation platform. Today, the range of medical services provided has been extended. The application provides physicians with access to their patients' medical records. Furthermore, it enables the patients to communicate and schedule appointments with the doctors. In addition, it offers reservation line treatment services to its users. In terms of pricing, various plans are offered, with either an annual fee, a monthly free or fixed fee per online consultation. For instance, the delay to get answer to an inquiry ranges from 3 to 30 minutes. This app regroups 50,000 visits/requests per day, more than 40 million registered users and 40,000 certified physicians ${ }^{18,19}$ ?

Public institutions have also started to test remote care models. In January 2015, the NDRC approved required pilot programs in five provinces. Hospitals from Beijing make medical resources available for remote care in the provinces of Ningxia, Guizhou, Tibet, Inner Mongolia and Yunnan. In Shenzhen, the Second People's Hospital was authorized to adopt a rare disease diagnosis platform where patients can upload information and have access to experts around the county. When, an expert consultation is given within 2 days. Patients can get access to online video conferencing in communities, village healthcare centres, pharmacies. Therefore, they remotely get medical advice from high-qualified doctors.

The remote consultation appears as a solution to geographical disparities in healthcare access in a context where disparities between urban areas and rural areas are deep and widening. In 2011, the ratio urban to rural healthcare expenses per capita was around $2.8^{20}$. This gap is due to the difference in healthcare price increase over the two last decades. If healthcare expenditures have been increasing 17 times in rural areas, they have increased 33 times in urban areas. As a comparison, this ratio is about 4 for the income per capita. Online consultation remove the physical topography constraint of the healthcare access. Internet users get access to the same

\footnotetext{
${ }_{18}$ China Mobile Health Market Research Annual Report 2012-2013, published by iiMedia Research consulting http://eng.hi138.com/computer-papers/internet-research-papers/201305/439592_20122013-annual-report-ofchina-mobile-healthcare-market.asp\#.VnENmtATH8s accessed September 2017

19 « Digital diagnoses: a remedy for the mainland's healthcare ills », September 2013

http://economists-pick-research.hktdc.com/business-news/article/International-Market-News/Digital-diagnoses-aremedy-for-the-mainland-s-healthcare-ills/imn/en/1/1X000000/1X09U8HV.htm accessed September 2017

${ }^{20}$ China National Health Development Researcher Center
} 
level of quality whatever the inhabitant's location and the same price. So far, the situation is quite different with a level of quality depending on the healthcare facilities level and a drastic variation in the healthcare price. Today, the healthcare system pricing is completely decentralized. Internet may unify the pricing policy of healthcare suppliers, at least for the out-patient consultations.

Besides, online consultations emerge as an alternative entry point into the healthcare system versus a visit a doctor in a level-3 hospitals. Earlier in this book, we have presented the reforms to push for referral family doctors to become the standard entry point as a means to redefine the patient's pathway in the healthcare system, in order to limit the demand for level-3 and 3A hospitals. Up till now, this reform has largely failed to enforce a new patient's pathway, as it bumps into the reluctance of the demand. The level of qualification of such doctors has not met the expectation of the demand yet. On the other hand, the digital path seems to succeed where the traditional solution has failed. Many patients seem quite open to getting online a first diagnosis a qualified physician at an affordable cost is realistic, prior to physically going to the hospital.

However, the question of the personal data confidentiality is a crucial issue. All medical information flows and is stocked through systems managed by private for-profit internet firms that maybe tempted to monetize such information. Wechat, the Tencent group star app, is a perfect example, as it is widely used for all purposes in many e-health situations, without much control over the usage of data. So far, the regulation is insufficient to guarantee a complete personal data confidentiality as well to prevent the use of this data for screening purposes. But is it realistic to imagine that such a regulation can be implemented?

Besides, these remote consultations present some other drawbacks. By definition, the patient is not physically seen by the doctor. Some information that cannot be caught by a virtual observation of the patient (it could be his gesture, some medically noticeable marks on his skin as examples) may be relevant for the medical diagnosis. Besides, in case of medical error, the legal responsibility of the physician is not clearly defined. There is not a clear regulation on remote doctor consultation. Another point is the prescription of drugs. In China, the deliverance of drugs is part of the consultation. For a physical medical consultation, the patient gets the adequate drugs prescription from the physician during the visit. For an online medical consultation, it is not possible for the patient to get the drugs during the visit and has to go out to a sometimes distant pharmacy. This brings about the question of online sales prescription drugs. Until now, only the over-the-counter drugs are allowed to sell online. ${ }^{21}$

\section{Integrated model of online-offline services}

Moving beyond simply offering on one side online services and on the other side physically located healthcare services, Internet companies explore a new scheme where these two services are integrated into a same model.

Alibaba Group is one of China's internet giant, initially specializing in online retail, similar to Amazon in US. It is a very good example in the sense it has a comprehensive and integrated strategy concerning health.

It started with Alibaba Health Information Technology Ltd. or Alihealth as trading brand,

\footnotetext{
${ }^{21}$ See details on online purchase drugs below in the Chapter.
} 
offering online-based healthcare services. It has progressively widened its scope. In the course of the year 2014, Alibaba Group publicized to swap transactions of Tmall Online _ an online pharmacy _ to Alihealth. Since September 2014, the Chinese authorities approved the establishment of Alipay, to a financial affiliate of Alibaba Group, Ant Financial. Alipay is a privately owned bank. ${ }^{22}$

The «Future Hospital » program was launched in May 2014 by Alihealth. It proposes a platform between patients and hospitals, where hospitalizing activities are online. Alipay is the key of this integrated model.

On the patient side: It allows patients to register online and to pick up medical reports. If they have an Alipay account; they can link it to the hospital's service, to pay using their Alipay wallet. This service enable patients to avoid queues at the cashier desk. Two years after its release, this program accounts for 400 hospitals partners nationwide that offer reservation and payment services and has served over 50 million people through this service. The registered users are mostly rural inhabitants.

On the hospital side: First, hospitals must pay an entry ticket for them to get this service set up. Once available, «Future Hospital» healthcare platform stocks medical records at the individual level on behalf of the hospital. It sorts out patient according to the estimated degree of severity, allowing the hospital to propose some patients a remote consultation. This way, the medical staff can quickly deal with patients that do not genuinely need to come in to see a doctor. It also allows to identify patients that needed services that will make the hospital money. These services lead to loosen pressures on level-3 hospital crowding. In addition, they generate a new sources of revenue, through online consultation. It may ease the transition away from current profit model heavily relying on drug sales from the hospital. Indeed, revenue directly stemming from online consultations as well as indirect revenue from patient selection can ease this reliance on medicine sales. The Central Hospital of Wuhan comes as a vivid example of this move in hospital profit model based on medical services. The IT system of this hospital is now completely dependent on « Future Hospital » healthcare platform. ${ }^{23}$

In a showcase program, Alibaba demonstrated its vision of the future of mobile healthcare. The firm proposes an integrated model of online-offline services. A villager, who lives in a remote fishing village of Hubei province, called a hospital several hundred kilometers away, and spoke to a doctor. The doctor wrote an online prescription, which the villager purchased at an Alibabaaffiliated online pharmacy. The drugs arrived the next day and the villager paid the delivery person. There was no long bus ride, no standing in lines to make an appointment, no waiting for the doctor. This view will revolutionize the way rural communities everywhere access healthcare services. ${ }^{24}$

\footnotetext{
${ }^{22}$ https://www.wsj.com/articles/alibaba-affiliate-wins-approval-to-start-private-bank-1411970203 accessed September 2017

23 https:/ / healthintelasia.com/alihealth/

accessed September 2017

http://technode.com/2015/04/24/alibaba-affiliates-future-hospitals-can-access-chinese-medical-data/

accessed September 2017

${ }^{24}$ http://www.chinabiotoday.com/articles/20160219

accessed September 2017
} 
This flow allows a much improved efficiency of the healthcare system efficiency. It may succeed where health authorities still struggle despite repeated attempts over at least three decades: to change the hospital's profit model based on drugs' sale to an alternative but profitable one. Besides, it represents one of the first cross-hospital consolidated patient databases in many Chinese provinces.

However, it introduces different downsides, such as:

- A possible systematic selection of patients

- Concerns about private data collection, especially in the Chinese context, where public services have been relatively slow to digitize their databases. How to preserve public interest when this public mission is delegated to a for-profit enterprise?

\section{Improving communication between patients and physicians}

The Chinese population has generally speaking a great appetite for information technology and social media and it is particularly the case for medical staff. As an example, most physicians run a microblog and $50 \%$ of them are Weibo users ${ }^{25}$.

On patients' side, a 2013 study from the Mc Kinsey consulting group showed that $17 \%$ of patients were using internet to choose the hospital where to go, this percentage reaching $28 \%$ for those under 25.

This creates an edge to improve communication between patients and medical staff, using these digital tools.

\section{Restoring the basics of communication}

There is a growing number of applications for patients to get information on healthcare facilities or doctors. Here, we can cite "the care voice", an app based on patient peer reviews and recommendation on medical health services. GBi with "Reframe Health". It has been introduced in 2015. This is the first app of clinical evaluation of mobile intervention. The focus is on chronic disease and on post-acute care.

\section{Mobile nurse stations}

eHealth proposes ways to better the quality of care delivery by improving the communication between medical staff and patients regarding their health status. Mobile nurse stations are one of them. First, when admitted in hospitals, patients are badged with a bracelet indicating an exclusive QR code. This allows to identify them accurately and reduce medical accidents caused by patient misidentification. Second, before examining patients, nurses can control the QR code with all digital health information associated with the QR code any her mobile device. She is

\footnotetext{
${ }^{25}$ McKinsey/DXY, 2012 Physician Survey, June 2011.
} 
then able to examine the patient and directly note information of the patient on her mobile device. The second phase allows to store and share patient data mode efficiently. Third, the patient himself is connected to the mobile nurse station. If a clinical event occurs or the patient needs help, the nurse staffing is alerted. This mobile nurse station also allows to evaluate nurses' performance based on reaction time documented by mobile nurse station.

Such mobile nurse stations are already in place in some local areas. For instance, in Hong Kong Special Autonomous Region (SAR), this type of station is used in all public hospitals. As a consumer, I can say that the relationship with nurses is first based on the recognition of the bracelet QR code with the mobile nurse station. This process then extends the visit time used. Yet, the cost for the hospital remains an obstacle to the widespread adoption.

So far, there is little of no scientific study fully analysing the effect of the mobile nurse station on the medical staff and patient communication or on the assessment of the healthcare provided improvement versus the risk it bears regarding the mishandling of confidential information.

\section{Electronic Health Record (EHR)}

Electronic Health Records (EHRs) are now in use in over 80 percent of developed markets and they are quickly becoming commonplace in China as well ${ }^{26}$. Electronic Health Record (EHR) enables physicians to record, manage and share health information at patient level in a very convenient way, by photo and audios.

According to Pacific Century Ventures, as of 2014, half of all tertiary hospitals in China use their own EHR system, as do $30 \%$ of urban health centres and $20 \%$ of rural hospitals. This growth is only expected to continue, with experts predicting $80 \%$ participation in tertiary hospitals by 2020 . Government officials also hope to implement EHRs in at least half of urban clinics and rural hospitals by 2020 as well. ${ }^{27}$

Figure 1: Electronic Health Record according to WHO

\footnotetext{
${ }^{26}$ https://www.clinicalleader.com/doc/overview-of-ehr-systems-in-bric-nations-0001 accessed September 2017

${ }^{27}$ http://paccentury.com/electronic-health-records-in-china/ accessed September 2017
} 


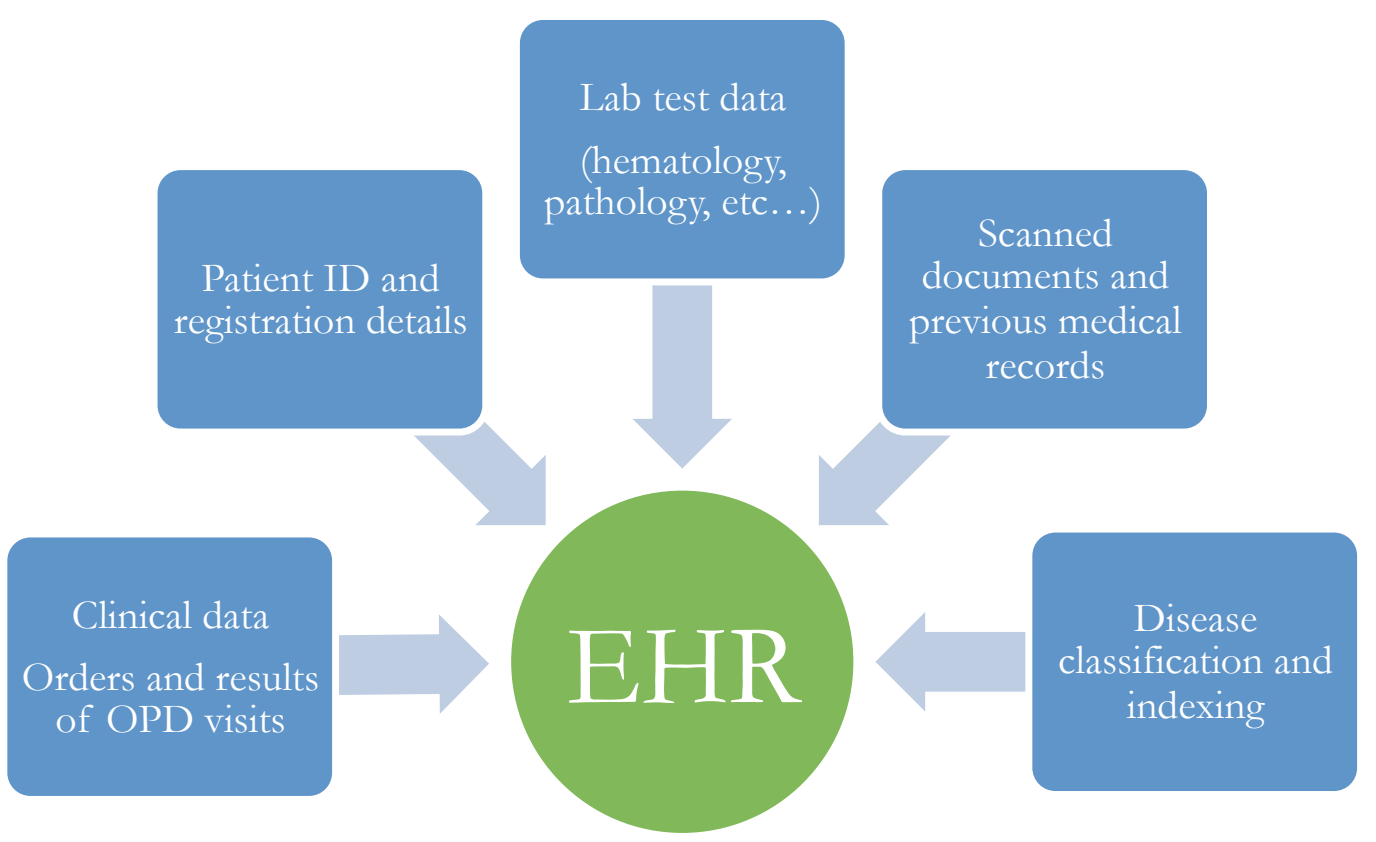

Source: Electronic Health Records: Manual for Developing Countries by WHO.

Xingshulin (Apricot Forest) is a mobile app that provide EHR Pile, Medical pocket -a content that includes frequently used clinical guidelines, labs handbook, pharmacopeia, and a medical literature with a bilingual medical literature library containing more than 300 scientific journals. So far, this application fails to make profits. Most revenue is from advertising. However, it still covers a small part of Chinese physicians (around 20\%). They expect to take advantage of the EHR resources in the future to generate profit.

The use of big data on individual health information raises increasing criticism regarding the risk of misuse of the information. In China's context of poor communication between medical staff and patient, the intention is to provide accurate information to deliver higher quality of care. However, thus mission of public service is delegated to a for-profit companies. Therefore, there is a risk that the collected information might be used at another purpose. Some guidelines can be imposed by the Central State. However, it may be insufficient versus the business and profit opportunities lying in such data.

\section{Communications between physicians}

Digital is also a useful tool to support the activity of physicians. The Clinical Decision Support Systems alerts physicians of secondary effects of the drugs they may prescribe, allergies as well as undesirable effects on patients. Introduced in the early 90's, it remains marginally used, as some apps offering the same services are actually easier to handle.

The behaviour of physicians is also modified by the use of internet. It fosters rapid dissemination of new technologies and the innovative procedures, changing the way patients are cured. Some virtual platforms propose research paper online, as Ding Xiang Yuan since 2000. This app is now regularly visited by more than 880000 physicians. 
DXY (DingXiangYuan) company is the leader on an online community for physicians, health care professionals, pharmacies and facilities. It proposes biomedical trade platform, job posting, medical knowledge -with medical information, academic journal, drug guides- social media, survey platform, data services. Launched in 2000, this healthcare information sharing website has more than four million registered users - most of them are medical professionals.

Tencent invested in DXY in 2014. For this giant of internet, this investment is aimed at exploring possible services to integrate into WeChat, the now essential app in China. With DXY, Tencent gets access to drug information and connects with millions of health professionals ${ }^{28}$.

\section{Patients are increasingly active actor of their health}

The topology of the Chinese territory explains that some areas are less populated than others. For obvious profitability motives, the density of healthcare centres can be very different and the network is scarce is some areas. Connected devices are then an option to support the follow-up of patients.

Wireless Heart Health program is emblematic of this tendency. Smartphones and cardiac sensors have been provided to 11,000 patients. The information collected is then sent to physicians for the follow-up. When the data reveals a potential problem, the patient is contacted and in some cases, she/he is admitted in a level 1-hospital for additional tests (96 healthcare centres have been selected). DuLife, a division of Baidu offers similar services and products.

These types of programmes promote e-health as a tool for a more equal healthcare access. To cite Xiaohui Yu from China Academy of Telecommunication Research of MIIT _CATR during the Brookings Institution conference in March 2014" "Our research shows that mobile technology can provide a means for China to meet challenges and achieve equal access to medical care ». During this same conference, Daryl West vice president of the study department of Brookings Institution reported the figure of 40,000 healthcare apps available on mobile phones.

\section{mHealth ${ }^{30}$ and connected devices}

Baidu has developed its mHealth (mobile health devices) and other connected devices. In 2014, it clearly stepped into the connected devices medical market with Dulife. The intelligent Bluetooth sports bracelet developed by Dulife, a fully owned subsidiary of Baidu, is a wearable health device. It collects and analyzes users' physiological indexes, such as blood pressure, body fat percentage, cholesterol level, and other medical information. From this information, some advises can be given on adapted physical exercises and proper nutrition. In addition, nutritional training for customers can be proposed.

Another example is iHealth, a leader in mobile medical devices. It proposes to monitor not only activities as sleeping or steps but also life signs as glucose, weights, body water, body fat, body

\footnotetext{
28 https://www.forbes.com/sites/ywang/2014/09/02/tencent-buys-minority-stake-in-chinese-healthcarewebsite/\#6026ea662e99

accessed September 2017

${ }^{29}$ From the report «Power to the patient: How mobile technology is transforming healthcare, The Economist Intelligence Unit, 2015

${ }^{30} \mathrm{mHealth}$ is an abbreviation for mobile health, a term used for the practice of medicine and public health supported by mobile devices. Definition from Wikipedia : https://en.wikipedia.org/wiki/MHealth
} 
mass, pulse rate via pulse sensor. It provides historical health documents available on smart devices. All the information can be shared automatically remotely.

As these examples of connected devices are used for pedometry and sleep monitoring, they can partially be compared to Fitbit, another wearable health device launched in 2007, in its updated version.

There are also connected devices specially dedicated to chronic disease management. The most common usage is for diabetes management. It can be counted around 500 apps for diabetes management. For instance, "Control Diabetes" is an app that proposes monitoring, documentation, a reminder function, help to education and online consultation services. There are around 200 physicians working for this app. D space or D nurse are also some other apps for diabetes monitoring.

\section{Cloud computing and big data initiatives}

Since the SARS episode, Chinese authorities have been very eager to set up a unified medical information system. Such a database would allow to monitor prevalence of infectious diseases. It may also ensure a control of the health condition of the population and allow to forecast health problem events as well as the early detection of unusual health problem.

Various initiatives have been taken in that sense. For instance, a public agency whose mission is precisely to launch Cloud-based health platform has been created. The Regional Health Information Networks (RHIN) is an information system linking hospitals to Community Healthcare Centers (CHCs). With this network, each hospital can create its own information systems and share it with other healthcare centres in their network. Actually, this program remains mostly at experimental stage, including a trial in Beijing starting from 2008, and was not been highly duplicated.

Another initiative is joint between Baidu and the Beijing municipal government It is called Beijing health cloud or Jiankangyun. It provides pre-diagnosis assessments for patients or medical staff using big data technology. There are three steps: monitoring, analysing and advising for a personalised (at the individual level) healthcare support.

Monitoring: from smart connected devices such as wristbands, medical information on, among others weight or blood pressure, will be collected at individual level and stocked on a Cloud;

Analysis: From this big data with information at individual level stored on a cloud-computing platform, analysis will be produced to screen population and evaluate very precisely the risk of healthcare expenses for each individual. Pre-diagnosis assessments will be available on request at individual level. It can be used to prevent illness or to plan and anticipate the public cost in healthcare demand; 
Advising: From this analysis, it will be possible to offer consultancy health services. Personalized healthcare products or services could be proposed to help people remain healthy. Personalized advice and coaching could be provided with a specific and individualized program on how to better one's health condition. With connected devices, additional offers may allow a follow-up on the individual, for instance through as remote electrocardiogram monitoring.

Baidu gave into a glimpse of the ultimate with the presentation in November 2016 of their virtual medial assistant called «Melody». This technology is designed to be the first port of call for a person feeling sick at home. A patient poses a health query to Melody, which responds in real time with further questions, and compares responses with Baidu's database of medical information. All that data gets crunched, and Melody then poses a possible diagnosis to a doctor who can then recommend next steps. ${ }^{31}$ Here is the ultimate use of the big data stored on the Cloud platform.

Here, the analysis of the big data on medical information supported on a cloud is supposed to be a tool for the regulator to accurately forecast healthcare expenses through big data analysis. The population can be accurately screened according to their propensity of illness and cost associated. It can also viewed as a good tool to help prevent illnesses and the spread of epidemics. As claimed by Li Mingyuan, vice-president of Baidu, the objective of this health Cloud platform is to better the social well-being. ${ }^{32}$ However, this health Cloud is also highly valuable in terms of differentiation of customers to monetize healthcare services products, in terms of selection of patients to set up health insurance premiums. The question is then what about the non-profitable group of consumers?

\section{Electronic Medical Records (EMR)}

Electronic Medical Records and Electronic Health record are at the individual level but they do not share the same focus. EHR collects information on the historical health status of the patient. This information allows to share the health information on the patient over the time. It enables a clinical follow-up of the patient by different doctors. The Electronic Health record collect information of the hospital admission. This information focus on the medical hospital's activity. It answer to the question: what was done by hospital's medical staff in terms of healthcare and for who _the population characteristics defined by their diagnosis and co-morbidity but also in terms of demographic variables.

In 2012, the MoH invested $\$ 9.5$ billion RMB for the development of medical data and the improvement of the information system in public Chinese hospitals. ${ }^{33}$ The main goal is the

\footnotetext{
${ }^{31}$ http://www.cnbc.com/2016/10/11/chinese-baidu-unveils-ai-health-chatbot-for-patients-and-doctors.html accessed September 2017

32 http:/ / www.chinadaily.com.cn/beijing/2014-07/31/content_18221458.htm accessed September 2017

${ }^{33}$ General Office of MOH of China: The notice of the General Office of the Ministry of Health on the promotion of pilot program of building electronic medical records as the core hospital information. http://wenku.baidu.com/view/e098b6020740be1e650e9a9f.html.

accessed September 2017 (in Chinese)

General Office of MOH of China: The notice of the General Office of the Ministry of Health on the issuance of the second batch of electronic medical records pilot cities and pilot hospitals. http:/ /wenku.baidu.com/view/e6226d0ebb68a98271 fefae6.html accessed September 2017 (in Chinese)

Lei J, Sockolow P. Sockolow, P. Guan, Q. Meng, J. Zhang BMC Medical Informatics and Decision Making 2013, 13:96
} 
creation of a standardized database on patient's characteristics:

- With unified the electronic format of the health information collected at the individual level;

- Yet, details of the information may still be different between local bureaus of health and with the national;

- Collection and storage of electronic medical records (EMR).

In some provinces such as Beijing, Jiangsu and Fujian pilot programs have been initiated to collect data following this newly defined protocol ${ }^{34}$. Yet, the development of big data-enabled solutions and Cloud system to improve the quality of healthcare is limited by geographical differences in hospital IT systems.

As a consequence, the focus is currently on building e-platforms to improve access and efficiency of the healthcare system. Amongst the major targets, one is to reach by 2020 a personal healthcare information system to cover the entire population. Different hospitals, counties, provinces have established digital databases for Electronic Health Record (EHR) and patient information. The objective is to build robust health information platforms in four levels (national, provincial, city-level and county-level) and achieve integration.

\section{Diagnosis Related Groups (DRG) and reimbursement}

To curb the increase in cost of healthcare and improve the inefficacies in healthcare access, one of the solutions is to change the reimbursement methods for hospitals. Until now, hospitals are reimbursed on a fee-for-service basis, but the development of IT makes it possible to develop alternative schemes, based on the pathology and not the act, in order to control costs more strictly.

Such schemes have been implemented in the US from the beginning of the 80 s and are now widespread across OECD countries. A categorization of pathologies, diagnoses and acts is setup. Each group defined is called Diagnosis Related Group or DRG.

Each DRG is defined by a sub-pathology as well as associated diagnoses and acts and procedures to be performed. This way, each patient can be affected to a DRG. Then, to each DRG is attributed a lump sum, based on the cost the hospital will have to bear for this precise type of patients. The advantage of this lump sum is that it is not correlated to the care actually performed but to what is theoretically necessary for each specific DRG.

The creation of the different groups requires elaborate IT systems, collecting at patient level information regarding all acts, procedures, diagnoses and co-morbidities.

China is currently testing such schemes, through pilot experiments, carried out in Beijing among others.

\footnotetext{
${ }^{34}$ China's health care reforms, Health International 2010 Number 10
} 


\section{Online drug market}

China's online retail market is the largest in the world, exceeding the US market size since 2013, and this market is growing very fast. Since 2012, the MoH and the NHFPC published directives in favor of the development of online pharmacies. China has become becoming the world's second largest online pharmaceutical market in less than five years, and there are already around 180 websites approved to sell over-the-counter (OTC) drugs online. ${ }^{35}$

So far, the most consumed products are vitamins and dietary supplements (VDS). Indeed, until 2016, the pharmaceutical laboratories were not authorised to sell prescription drugs online. That year was announced that authorization was imminent, but it hasn't been given as of today. In newspapers or from consulting group interviews (realised in Beijing, Shanghai and HK, from 2015 to 2017), the big internet groups are all anticipating that the lift of this ban on prescription drug e-commerce is just a matter of time, needed to overcome the reluctance of some stakeholder.

This has to be put in the context where, today, $80 \%$ of the drugs sales are done in public hospitals and are essential to their financial model. A fully fledged online drug market, including prescription drugs, is a pointed competition to the direct in-hospital drug sale. In the US, by comparison, 30\% of the OTC and prescribing drug sale are carried out on the internet. This explains their opposition to open the online market to prescription drugs.

For the consumer on the other hand, it should imply lower drug prices, but with questions regarding the quality of the product, in a context of proliferation of fake medicine drugs reaching the marketplace. The level of quality and the trust in any online market will depend on the level of guidelines and regulation set up by the authorities. Indeed, it is more difficult to control the drug sellers on the internet than those with a shop on the street corner.

The government has sought to implement a platform that would authenticate and track pharmaceutical products. In 2005, the State General Administration of Quality Supervision, Inspection and Quarantine (AQSIQ) first promote and then enforced the use of an electronic quality control system named Product Identification Authentication and Tracking System, or PIATS. This system was developed by a structure co-owned by AQSIQ and Citic 21CN. By mid of 2008, around 68,500 firms were using this system. It codes all the drugs listed in the national basic medicine categories as well as imported medicines. The target is to fight against fake medicine drugs, by enabling both retailers and consumers to easily check the authenticity of the products they purchase.

Later, Citic 21CN got approval from the China Food and Drug Administration (CFDA) to sell drugs on a third-party website. In 2014, Alibaba and Yunfeng bought control of Citic $21 \mathrm{CN}^{36}$ on Hong Kong stock exchange, holding $51.3 \%$ of CITIC $21 \mathrm{CN}$. The objective of Alibaba is to develop a pharmaceutical product information and selling platform. It can use the large pool of pharmaceutical product data detained by CITIC 21CN, combined with the Alibaba knowledge on

\footnotetext{
35 http:/ / daxueconsulting.com/e-pharmacy-in-china/ accessed September 2017

36 Alibaba, Yunfeng bought control of Citic 21CN for $\$ 171$ Million https://www.bloomberg.com/news/articles/2014-01-23/alibaba-yunfeng-to-buy-control-of-citic-21cn-for-171million

accessed September 2017
} 
e-commerce, cloud computing and big data analysis. Besides, Alibaba's Yao.Tmall is the Alibaba marketplace that aggregate diverse online pharmacy vendors.

As a result, PIATS is today outsourced by the China Food and Drug Administration to Ali Health, the health division of Alibaba. The managing structure has been renamed Alijiankang. This situation has been raising criticism, due to potential conflict of interests by both taking part in the regulation of pharmaceutical sales while simultaneously operating within that market. 19 big pharmaceutical companies including the two most powerful (Sinopharm Group Co. Ltd and Laibaixing Pharamcy Chain) took action to sue CFDA over the monitoring system. These firms alleged the arrangement concerning PIATS gave an unfair advantage to Ali Health ${ }^{37,38}$. In February 2016, China's food and drugs regulatory agency decided to freeze PIATS. After a few month, the implementation of PIATS resumed, with new conditions: participation of pharmaceuticals is now on voluntary basis and no longer mandatory as was previously planned. Besides, to placate the other operators in the sector, it was announced that pharmaceutical companies would be exempted from drug tracking fees for a period of three years. But what lies in store after that? ${ }^{39}$

Beyond the questions raised by a private, profit-driven enterprise collecting personal medical data, the company appears to be embroiled in a conflict of interest, in the sense that the company itself sells medication online. This gives Ali Health a major role in regulating healthcare products and in giving access to privileged information on those very same products ${ }^{40}$.

\section{New models of drug purchase}

If online market opens to prescription drugs, hospital will lose their monopoly situation and the advantage of being both the prescriber and the seller. Different scenarios can be imagined. The patient could visit a doctor and then buy online the prescribed drugs. Another scenario could be that the patient consults a doctor online and then, after a competitive bidding process, purchases through increased competition.

The online to offline prescription drug sale pilot model of Alihealth is based on such bidding process. First tested in 2014 for Shijiazhuang and Hangzhou, it is now available in major cities such as Beijing, Shanghai or Guangzhou. The patient can send a picture of prescription drug scripts and choose pharmacies after a bidding process. The selected pharmacy will sell the drugs and deliver them offline. A direct payment can also be done on Tmall drugstore (a division of Alibaba). The Scan drug electronic code allows the patient the acquire information on the drug product purchased. Prescription drug scripts can also be sent directly from hospitals that partner with Alihealth.

The online to offline $(\mathrm{O} 2 \mathrm{O})$ prescription drug sale model attracted other companies too.

\footnotetext{
37 http:/ / fortune.com/2016/02/21/cfda-ali-health-drug-monitoring/ accessed September 2017

38 http:/ / www.wsj.com/articles/ali-health-swallows-bitter-pill-as-china-halts-drug-monitoring-system-1456144563 accessed September 2017 39 "Ali Health to Launch New Third-party Drug Tracking Platform," Marbridge Daily, 10 May 2016.

40 "China Pharmacies Urge Abolition of Alibaba Health Drug Tracking Platform," Reuters, 24 February 2016, http://mobile.reuters.com/article/idUSKCNOVXOUX accessed September 2017
} 
For instance, the insurance giant Pingan has a division called Yihaodian that is accredited to sell OTC list A drugs. GSK, the British pharmaceutical company, opened an official shop on Tmall, while some apps (as Ehaoyao and Qumaiyao) launched their O2O drug sale platform.

\section{Justification of government intervention}

How to ensure competitive conduct on the market. Under which circumstances state intervention is desirable? The public interest approach may justify the state intervention. There are 4 mains reasons:

- The asymmetric information between consumers and providers. The implementation of the PIATS is a way to compensate this lack of information for the consumer. However, it places a private firm in a dominant position.

- The externality that happens when costs or benefits affect other agents than those directly concerned by the transaction. Pollution is an easy to understand example. The drug market is another good example. The control of drug quality ensures a positive externality in a public health perspective.

- The concept of public good: good and services defined as a pure public good need to have specific properties. National defence, education (at least for a basic one) and healthcare access (for a defined basked established as a need for universal access are some examples.

\section{The upcoming challenges for e-health}

\section{Constraints of data collection}

To collect and process information, the medical staff has to dedicate part of their time to these administrative tasks. If digitalization has many advantages, on the flip side the time dedicated to it comes at the expense of pure medical attention. For instance, nurses, in addition to their usual tasks, have now to scan the bracelet of their patients to check their identity and then check the tag on the drugs before given them to patients. Lili Hua, a nurse of a level -3 hospital in Beijing explained the cumbersome administrative procedures since the implementation of the electronic medical system. She said that the time spent with the patient is even less than before even if this new constraint leads to reduce the medical errors". Overall, these changes lack scientific studies to assess the global effect on the healthcare provided to patients.

Figure 1 displays the tasks to be done by the nurse at each visit control to a patient

\footnotetext{
${ }^{41}$ Interview in Beijing, November 2015. Name has been modified.
} 


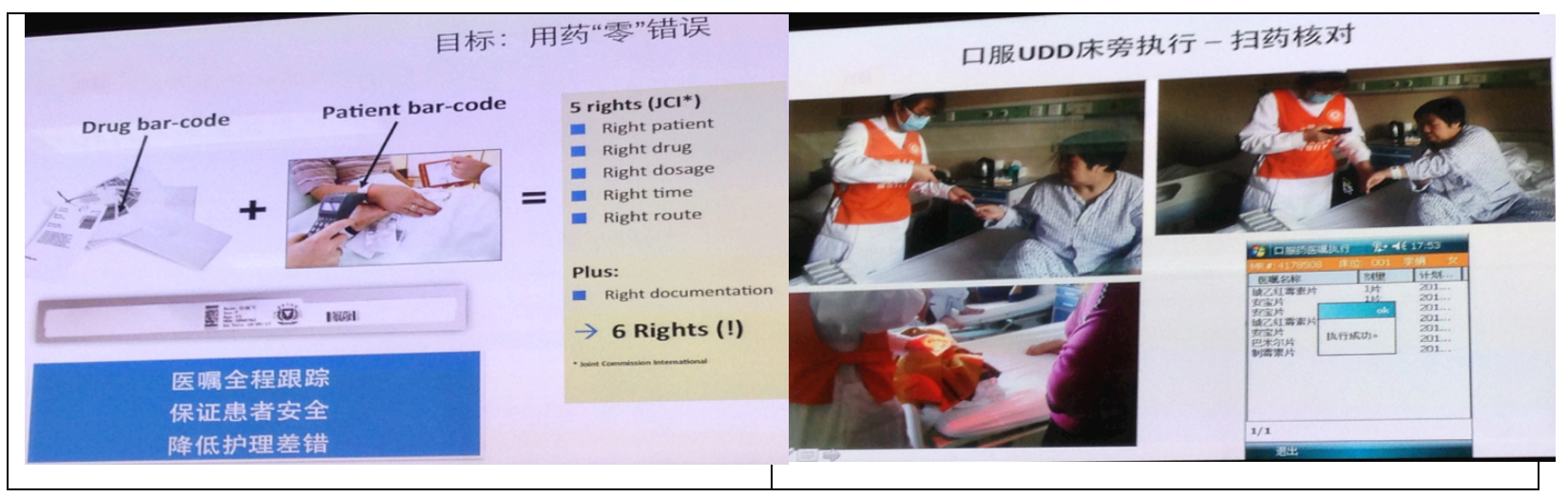

\section{Confidentiality of data and patient privacy}

How to deal with the confidentiality of the data? This question is central to the development of e-health, not only in China but in any country.

Figure 2 shows the results come from a survey carried out by the think tank Economist Intelligence Unit regarding e-health interviewing $144 \mathrm{CEO}$, managers and strategy managers of healthcare institutions, both public as private, pharmaceutical companies as well as medical devices producers, in 23 countries. Surprisingly, for interviewees from the public sector, patient privacy is the main obstacle to development of e-health.

According to Robert B. McCray, president and CEO de la Wireless-Life Sciences Alliance ${ }^{42}$, «If people won't use the technology because of data breaches, we run the risk of losing the benefits of these technologies ». And the president and strategy director of Samsung Electronics, Young Sohn, adding ${ }^{+3}$ " privacy is probably the single biggest issue of our time ».

Figure 2: survey result / challenges to health industry adoption of mobile technologies

\footnotetext{
${ }^{42}$ From the report «Power to the patient: How mobile technology is transforming healthcare" , The Economist Intelligence Unit, 2015

43 «Power to the patient: How mobile technology is transforming healthcare” , The Economist Intelligence Unit, 2015
} 
Prof. Carine MILCENT

Carine.milcent@psemail.eu

CNRS - PSE

Which of the following do you think are currently the biggest challenge for health industry adoption (eg. by hospital, doctors of pharmaceutical firms) of mobile health technologies?

Please select top three. (\% of respondents)

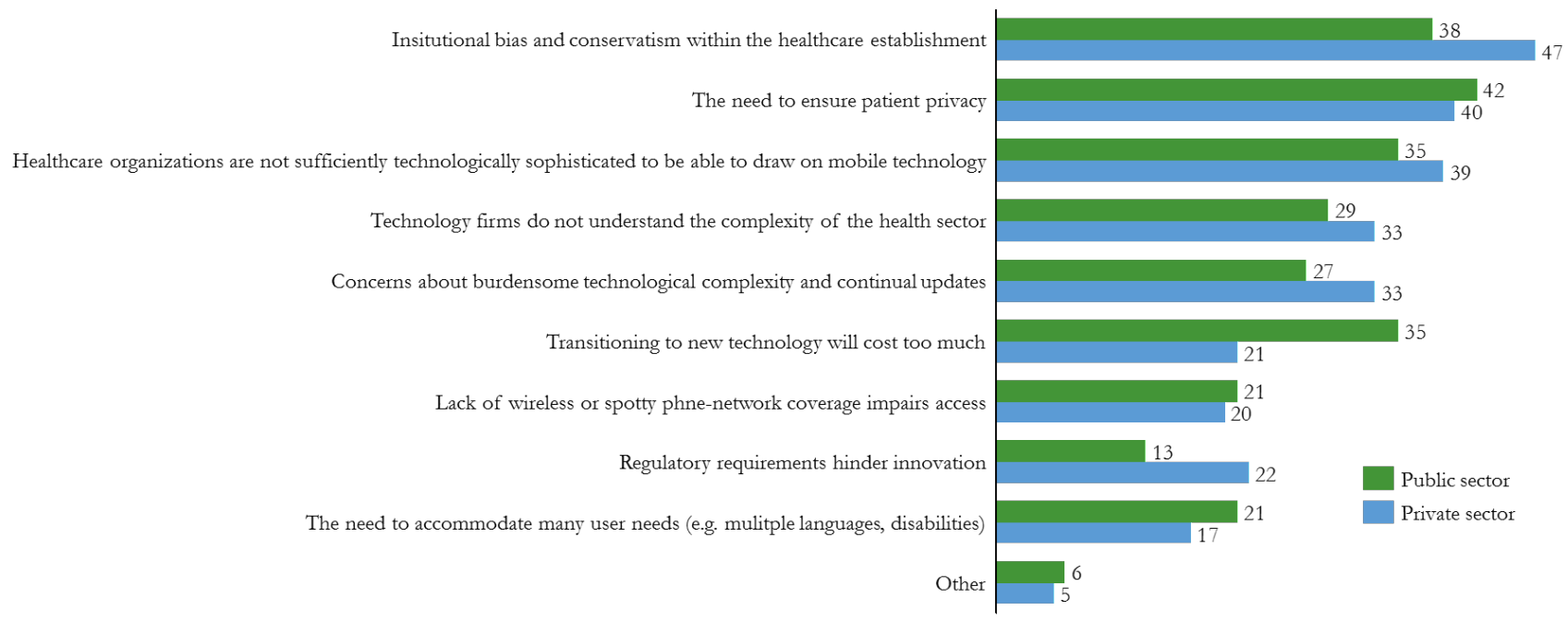

Another point is the inequity generated by connected objects. If the financial dimension may be a minor issue, the demographic dimension is central (Figure 3), with older generation less prone to be comfortable with digital technologies.

\section{Figure 3: survey result / most important audience for mobile health}

Which age demographics are currently the most important audience for mobile health? Please select top two. (\% of respondents)

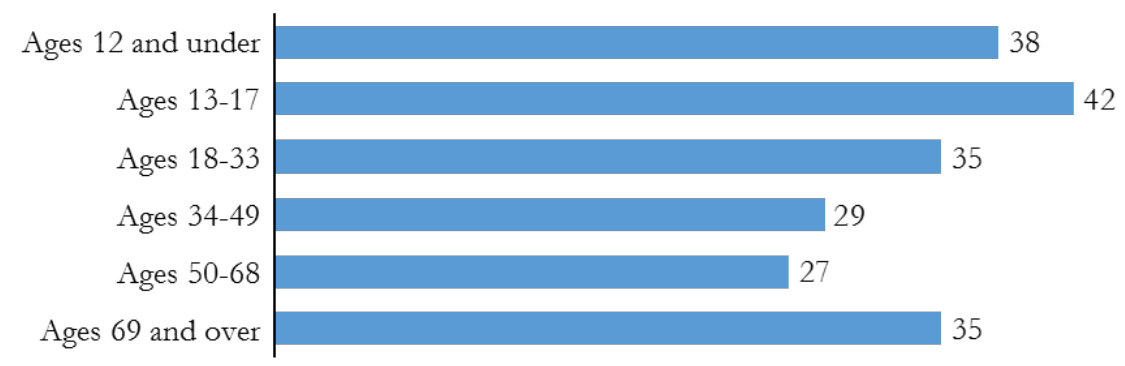

Without being totally excluded, the elderly population is the less exposed to the e-health and mHealth. Even if the healthcare system reform is putting the emphasis on digital tools, they still need to be duplicated in a more tradition fashion for the elderly. For instance, for the online registration system, a phone service has been implemented as well as a simplified app. However, the speed of voice of automated answering machines with pre-recorder instructions given are not always easily understood by senior citizens. In some areas, "real-world" help desks are opened to help the elderly to navigate this digital environment. But what about the areas without these helps? 


\section{Conflicts of interests}

Concerns about possible conflicts of interests have become increasingly prominent in the light of recent scandals. I will illustrate this paragraph with stories focusing on some of the internet giants (Baidu, Alibaba, and Tencent), with an emphasis on the implications for the Chinese health system under construction.

The Baidu Tieba Forum, part of Baidu, is an Internet forum administrator. It contains more than 10,000 sub-forums, including forums aimed at exchanging healthcare information. In recent months, a number of scandals have erupted ${ }^{4}$ over the capacity for private companies to take control of these non-commercial forums, allowing ads for medical products of dubious quality. The flashpoint for this was the case of a forum on haemophilia (a blood disorder). It was displaying advertisements that extolled the virtues of healthcare providers that turned out to be unlicensed and of poor quality. More recently, in May 2016, a student who died of cancer had published a long post where he placed the blame squarely on Baidu for irresponsibly exaggerating the capabilities and quality of the hospital where he chose to have treatment.

As explained above, the Product Identification Authentication and Tracking System, or PIATS was outsourced by the China Food and Drug Administration to Ali Health, a division of Alibaba. Beyond the questions raised over a private, profit-driven enterprise collecting personal medical data, the company appears to be embroiled in an array of conflicts of interests, in the sense that the company itself sells medication online (Alibaba announced that the running of online pharmacy Tmall Online would be transferred to Ali Health) ${ }^{45}$. This gives Ali Health a major role in regulating healthcare products and privileged information on those very same product.

In conclusion, we can say that digital healthcare offers multiple sources of improvement but is not in itself a fully-fledged solution to fix all inefficiencies of the Chinese healthcare system. It needs to be integrated into a strong-willed set of policies, including a redefined patient journey and clear monitoring of private actors carrying out missions of public service. This is obviously still a work in progress.

\section{Conclusion}

One solution to puzzle out the inefficiency of the Chinese healthcare system may be to foster the development of managed care organizations. Integrated core services from diagnosis to followup would be provided and managed by private insurances. The e-consultations would be a way to offer a very high quality panel of doctors. These doctors, working otherwise $n$ governmentowned hospital, would provide their services remotely. So far, the main barrier is the level of quality provided by private hospitals. The slow development of high-quality private hospitals is an obstacle as well as government-owned status of high-quality level-3 and level-3A hospitals. Currently, some pilot programs have been launched to encourage a cooperation between private health insurers and level-3 or level-3A hospitals. For the patient, the advantage is a rapid access

\footnotetext{
44 Zhou Dongxu, "Baidu Backtracks on Letting Private Firms Run Popular Forums," CaixinOnline, 13 January 2016, http://english.caixin.com/2016-01-13/100899054.html; Belinda Cao and Stephen Stapczynski, "Baidu Retreats on Chinese Private Hospital Advertising Boycott," Bloomberg, 6 April 2015.

${ }^{45}$ The relationship between the branches of the Alibaba group and Ali Health have been simplified here.
} 
Prof. Carine MILCENT

Carine.milcent@psemail.eu

CNRS - PSE

to healthcare from benign illnesses to severe pathology. For the supply side, the advantage is total control on the patient's pathway and a complete knowledge of the historical medical file owing to big data.

Up to now, according to the private investors, the public simply lacks trust in big data initiatives concerning their health. Health cloud, though, is valuable in terms of social well-being improvement. Privacy concerns makes a social barrier that has to be overstepped to fully thrive the health cloud. However, is that what is desired by the population? In terms of health prevention and healthcare expenses control, the big data is a really powerful tool. However, in terms of equity, the answer is not straightforward. A healthcare system based on a sharp screening of the population will disclose and uncover the population with a high propensity of heavy healthcare expenses. The question of a privately insurance coverage for this disadvantaged population will be even shriller.

With a pooling population of patients without information on the health condition, the healthcare system could be based on a percentage of the wage. With the development of the health cloud and its utilisation, such a financing scheme is less and less plausible.

Could we say that the veil of ignorance has certain virtues? 
Prof. Carine MILCENT

Carine.milcent@psemail.eu

CNRS - PSE

Su Y, Liu J. L, Wang Y, Yi X. M. The idea about the mode of a patient- centered modern clinic. Journal of Medical Postgraduates. 2006;19(1):74-78.

Guo R, Miao Z. M, Wei G, Xing S. C, Zhang Y. The present situation and suggestions of the domestic appointment registration of hospital. Progress in Modern Biomedicine. 2012;12(7):1357-1360

Huang M. Exploration and practice about outpatient appointment registration service mode. Gansu Journal of Traditional Chinese Medicine. 2011;24(1):59-60

Yin X. Q, Huang Z. Z, Huang L. J. Design and research on appointed outpatient registration system in modern hospital. Hospital Digitalization. 2010;31(12):48-53.

Xu Y. X, Ding H. X. Current situation analysis of the hospital outpatient appointment services. Clinical Medical Engineering. 2012;19(1):105-106.

Yin X. Q, Huang Z. Z, Huang L. J. Design and research on appointed outpatient registration system in modern hospital. Hospital Digitalization. 2010;31(12):48-53.

Chen J. H, Tu S. G, Xiong H, Xu N. Z. Practice of mobile phone real-name system appointment registration. Chinese Nursing Research. 2012;26(1):170-171

Huang M. Exploration and practice about outpatient appointment registration service mode. Gansu Journal of Traditional Chinese Medicine. 2011;24(1):59-60.

Yu W, Yu X, Hu H, Duan G, Liu Z, Wang Y Use of hospital appointment registration systems in China: a survey study. Global Journal of Health Sciences, 2013 ; 5(5):193-201

McKinsey Consulting Group analysis, 2015 https://fr.slideshare.net/fle864/20150402-chic-mck-e-health-in-china-vf accessed September 2017

Lei J, Sockolow P. Sockolow, P. Guan, Q. Meng, J. Zhang BMC Medical Informatics and Decision Making 2013, 13:96

Zhou Dongxu, "Baidu Backtracks on Letting Private Firms Run Popular Forums," CaixinOnline, 13 January 2016, http://english.caixin.com/2016-01-13/100899054.html; Belinda Cao and Stephen Stapczynski, "Baidu Retreats on Chinese Private Hospital Advertising Boycott," Bloomberg, 6 Ap 